\title{
VULNERABILITY OF PUBLIC DRINKING WATER SUPPLIES IN NEW JERSEY TO PESTICIDES
}

Beginning in 1993, Safe Drinking Water Act (SDWA) regulations required the 626 large community water systems in New Jersey to monitor their 2,600 wells and 45 surface-water intakes quarterly for 23 pesticides. Monitoring costs would increase consumers' water bills by \$6.4 million each year. The New Jersey Department of Environmental Protection (NJDEP) can waive monitoring requirements for wells or intakes that are not vulnerable to pesticide contamination.

The U.S. Geological Survey (USGS), in cooperation with NJDEP, determined the vulnerability of wells and surface-water intakes to pesticide contamination on the basis of hydrogeology and pesticide use. The NJDEP estimated that because many wells and intakes are not vulnerable to contamination by pesticides, monitoring waivers will save taxpayers at least $\$ 5.1$ million annually for a one-time study cost of $\$ 1$ million.

\section{Vulnerability of Public- Supply Wells}

- Of the 1,955 public-supply wells for which data are available, the vulnerability to pesticides was low for $26 \%$, medium for $70 \%$, and high for $4 \%$ (fig. 1 ).

- Pesticides were detected in samples from 6 of 90 wells.

- Five pesticides - atrazine, dinoseb, simazine, metolachlor, and metalaxyl-were detected. Concentrations ranged from 0.01 to 2.2 micrograms per liter $(\mu \mathrm{g} / \mathrm{L})$.

- No pesticide concentration exceeded a U.S. Environmental Protection Agency (USEPA) maximum contaminant level (MCL).

- Pesticides were not detected in any wells in the lowvulnerability group but were detected in $19 \%$ of the wells in the high-vulnerability group (fig. 2).

- Pesticides were detected most frequently in agricultural areas (figs. 3 and 4).

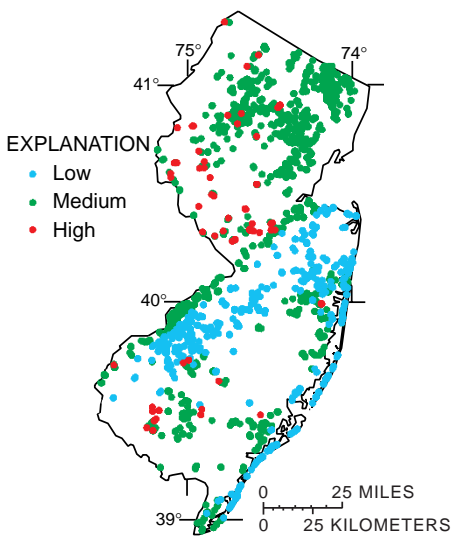

Figure 1. Location of wells vulnerable to pesticides.

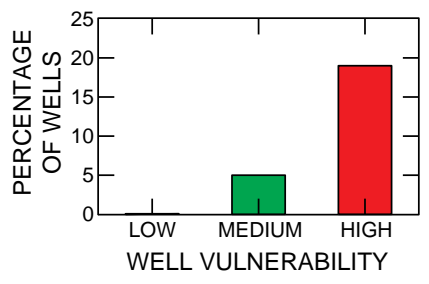

Figure 2. Pesticide detection by well vulnerability.

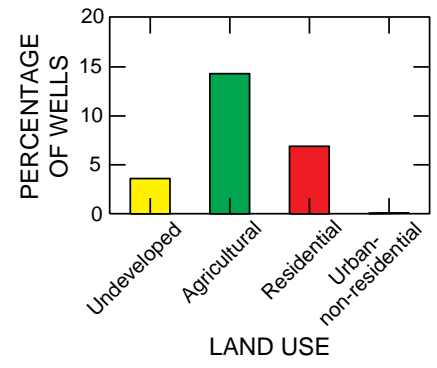

Figure 3. Pesticide detection by land use.

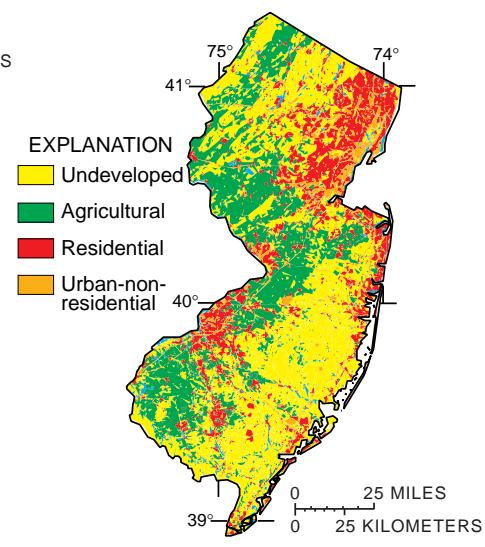

Figure 4. Land use.

\section{Vulnerability of Public- Supply Intakes}

- Of the 45 drainage basins with public-supply intakes, $20 \%$ are not vulnerable to contamination by agricultural pesticides.

- The 45 basins are more vulnerable to contamination by triazine (figs. 5 and 6) and acetanilide herbicides than by organophosphates and carbamate insecticides.

- Pesticides were detected in 46 of the 76 samples collected near 7 intakes.

- Ten pesticides were detected. The most frequently detected pesticides were atrazine, metolachlor, simazine, and alachlor. Concentrations ranged from 0.03 to $5.5 \mu \mathrm{g} / \mathrm{L}$.

- No pesticide concentration exceeded a USEPA MCL.

- Pesticides were detected more frequently and concentrations were greater during high flow than during low flow.

- Pesticides were not detected in samples collected near publicsupply intakes in the low-vulnerability group but were detected near $75 \%$ of the intakes in the high-vulnerability group (fig. 7).
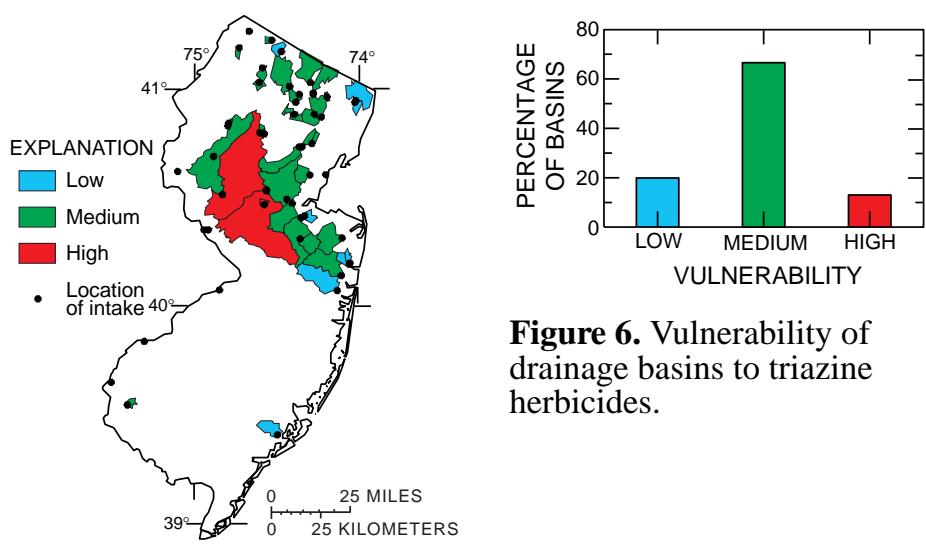

Figure 6. Vulnerability of drainage basins to triazine herbicides.

Figure 5. Location of drainage basins vulnerable to triazine herbicides.

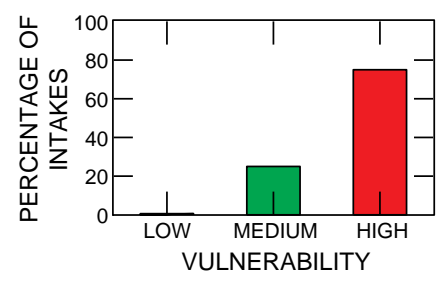

Figure 7. Pesticide detection by intake vulnerability. 


\section{Monitoring Waivers and Cost Savings}

- NJDEP estimated that monitoring costs to water suppliers would increase by $\$ 6.4$ million per year if all 23 pesticides were determined using USEPA-approved methods.

- NJDEP decided that monitoring costs could be reduced by providing waivers for analyses for pesticides that are not used in New Jersey or for pesticides that were not previously detected in water samples. NJDEP determined that only 10 of the 23 pesticides need to be monitored at vulnerable wells (Louis and others, 1994).

- For wells, an estimated $\$ 5$ million will be saved annually because of monitoring waivers that would result in reductions in the number of pesticides that need to be analyzed and the number of wells to be sampled.

- For public-supply intakes, an estimated $\$ 0.16$ million will be saved annually because of a reduction in the number of pesticides analyzed and because samples will be collected only twice a year, during high-flow and low-flow conditions.

\begin{tabular}{|c|c|c|c|}
\hline \multicolumn{4}{|c|}{$\begin{array}{c}\text { Costs of vulnerability studies and estimated } \\
\text { monitoring savings }\end{array}$} \\
\hline $\begin{array}{c}\text { Water-supply } \\
\text { source }\end{array}$ & $\begin{array}{c}\text { One-time } \\
\text { study costs } \\
\text { (millions) } \\
\end{array}$ & \begin{tabular}{c|} 
Annual \\
savings \\
(millions)
\end{tabular} & Type of waiver \\
\hline Wells & $\$ 0.7$ & $\$ 5.0$ & $\begin{array}{l}\text { Number of pesticides } \\
\text { Number of sampling points }\end{array}$ \\
\hline Intakes & $\$ 0.3$ & $\$ 0.16$ & $\begin{array}{l}\text { Number of pesticides } \\
\text { Frequency of sampling }\end{array}$ \\
\hline
\end{tabular}

\section{Methods of Determining Vulnerability}

- The vulnerability of a public-supply well or intake to contamination is defined by the following equation: Vulnerability $=$ Sensitivity + Intensity

- Numerical rating models were developed and tested by using a geographic information system (GIS) to group sites according to their relative vulnerability (high, medium, or low) to contamination by pesticides.

- Water samples were collected by USGS personnel and analyzed at a Rutgers University laboratory (Mogadati and others, 1994) to test model results.

\section{Model for public-supply wells}

- Hydrogeologic sensitivity of a well was based on three variables-distance from the aquifer outcrop area, organicmatter content of the soils at the well, and depth to the top of the open interval of the well.

- Pesticide-use intensity near wells that are in hydrogeologically sensitive parts of an aquifer was based on three variablessurrounding land use, distance from the nearest parcel of agricultural land, and distance from the nearest golf course.

- Wells in the low-sensitivity and low-intensity groups were rated as low vulnerability, whereas wells in the high-sensitivity and high-intensity groups were rated as high vulner-ability. All other wells were rated as medium vulnerability (Vowinkel and others, 1994).

- Water samples from 90 wells were analyzed for 140 pesticides.

\section{Model for public-supply intakes}

- Pesticide-use intensity near a public- supply intake was based on two variables-percent agricultural land and application rate of a pesticide in agricultural areas in the drainage basin.

- The 45 drainage basins with intakes were grouped by their vulnerability (high, medium, or low) to contam-ination by four groups of pesticides - organophosphate, triazine, acetanilide, and carbamate (Buxton and Stedfast, 1994).

- Seventy-six samples collected near 7 surface-water intakes were analyzed for 18 pesticides from the 4 pesticide groups at a Rutgers University laboratory.

- Samples were collected during high-flow and low-flow conditions.

---E.F. Vowinkel, R.M. Clawges, D.E. Buxton, and D.A. Stedfast, U.S. Geological Survey and J.B. Louis, N.J. Department of Environmental Protection

\section{References}

For more information concerning methods and results of the studies reported here, refer to the four reports listed below, which were published in the proceedings by Weigman, D.L., ed., 1994, New directions in pesticide research, development, management and policy, Proceedings of the Fourth National Conference on Pesticides, November 1-3, 1993, Virginia Water Resources Center, Blacksburg, Va., 852 p.

Buxton, D.E., and Stedfast, D.A., 1994, Estimating the vulnerability to pesticide contamination of drainage basins used for public supply in New Jersey, p. 184-199.

Louis, J.B., Sanders, P.F., and Bono, P.M., 1994, Implementing a program to assess the vulnerability of New Jersey's drinking water supplies to pesticide contamination, p. $167-183$.

Mogadati, P.S., Wang, Sensui, Roinestad, K.S., and Rosen, J.D., 1994, Significant improvements in multiresidue pesticide analysis, p. 409-427.

Vowinkel, E.F., Clawges, R.M., and Uchrin, C.G., 1994, Evaluation of the vulnerability of water from public supply wells to contamination by pesticides, p. 495-510.

\section{Acknowledgments}

The authors thank P.M. Bono and P.F. Sanders of NJDEP, Division of Science and Research, and C.G. Uchrin of Rutgers University for their technical support. The analytical methods services provided by P.S. Mogadati, Sensui Wang, K.S.

Roinestad, and J.D. Rosen of Rutgers University enabled a scan for a large number of pesticides that was unavailable elsewhere.
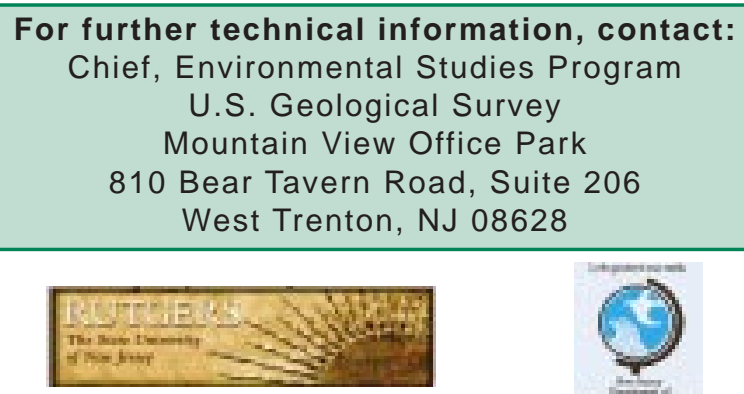